\title{
Esophageal stenting for benign and malignant disease: European Society of Gastrointestinal Endoscopy (ESGE) Cascade Guideline
}

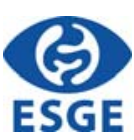

\section{(ㄷ)(1) $\odot \odot$}

\section{Authors}

Alanna Ebigbo ${ }^{1}$, John Gásdal Karstensen², Lars Aabakken³${ }^{3}$ Mario Dinis-Ribeiro ${ }^{4}$, Manon Spaander ${ }^{5}$, Olivier Le Moine ${ }^{6}$, Peter Vilmann², Uchenna ljoma7 ${ }^{7}$ Chukwuemeka Osuagwư ${ }^{7}$, Gideon Anigbo ${ }^{8}$, Mary Afiheni ${ }^{9}$, Babatunde Duduyemi ${ }^{10}$, Hailemichael Desalegn ${ }^{11}$, Thierry Ponchon ${ }^{12}$, Cesare Hassan ${ }^{13}$

Institutions

1 Department of Gastroenterology, Klinikum Augsburg, Augsburg, Germany

2 Gastro Unit, Division of Endoscopy, Copenhagen University Hospital Hvidovre, Copenhagen, Denmark

3 Endoscopy, Oslo University Hospital - Rikshospitalet, Oslo, Norway

4 CIDES/CINTESIS, Faculty of Medicine, University of Porto, Porto, Portugal

5 Department of Gastroenterology and Hepatology, Erasmus Medical Centre Rotterdam

6 Gastroenterology Department, Erasme University Hospital, Brussels, Belgium

7 Department of Gastroenterology, University of Nigeria Teaching Hospital, Ituku-Ozala, Nigeria

8 Department of Medicine, Enugu State University Teaching Hospital, Enugu, Nigeria

9 Department of Medicine, Kwame Nkrumah University of Science and Technology, Kumasi, Ghana

10 Department of Pathology, Kwame Nkrumah University of Science and Technology, Kumasi, Ghana
11 Department of Internal Medicine, St. Paul's Hospital Millenium Medical College, Ethiopia

12 Gastroenterology and Endoscopy, Edouard Herriot Hospital, Lyon, France

13 Endoscopy Unit, Nuovo Regina Margherita Hospital, Rome, Italy

submitted 28.3.2019

accepted after revision 2.2.2019

Bibliography

DOI https://doi.org/10.1055/a-0898-3523 |

Endoscopy International Open 2019; 07: E833-E836

(c) Georg Thieme Verlag KG Stuttgart · New York

elSSN 2196-9736

Corresponding author

Cesare Hassan, MD, Endoscopy Unit, Nuovo Regina

Margherita Hospital, Via Morosini 30, Rome 00153, Italy

Fax: +39-06-58446533

cesareh@hotmail.com

\section{Introduction}

Dysphagia and obstruction are among the most common indications for upper gastrointestinal endoscopy in African countries [1]. In a survey conducted by the European Society of Gastrointestinal Endoscopy (ESGE) International Affairs Working Group (IAWG), benign esophageal strictures as well as malignant upper gastrointestinal obstruction were reported as some of the most prevalent diseases leading to gastrointestinal endoscopy [1].

Management of esophageal obstruction may vary, depending on the cause of obstruction as well as the availability of re- sources. According to the ESGE original guideline, it could involve, for example, stent placement, radiotherapy/brachytherapy, or bypass surgery [2]. For resource-limited settings, however, a number of additional factors need to be considered before recommendations can be made. These involve economic considerations and resource availability. Furthermore, patients in low-resource settings presenting with malignant esophageal obstruction are often unfit for surgery due to presentation with advanced malignant disease as well as comorbidities such as HIV/AIDS and tuberculosis [3]. For such situations, self-expanding metal stents (SEMS) of the esophagus may provide a suitable palliative option $[3,4]$. 
- Table 1 Level of treatment care.

\begin{tabular}{|l|l|}
\hline Predefined level & Definition \\
\hline I: Basic & $\begin{array}{l}\text { Core resources or fundamental services absolutely necessary for an endoscopy care system to function. By definition, a health } \\
\text { care system lacking any basic level resource would be unable to provide endoscopic service to its patient population. It includes } \\
\text { diagnostic procedures (gastroscopy and colonoscopy) as well and fundamental monitoring abilities (blood pressure, basic } \\
\text { blood biochemistry). }\end{array}$ \\
\hline $\begin{array}{l}\text { Limited level: Second-tier resources or services that produce major improvements in outcome, such as increased survival, but } \\
\text { that are attainable with limited financial means and modest infrastructure. It includes minor endoscopic procedures to im- } \\
\text { prove major clinical outcomes (i. e. sclerotherapy/adrenaline injection, band ligation, plasma expanders, basic surgical inter- } \\
\text { ventions). }\end{array}$ \\
\hline $\begin{array}{l}\text { Enhanced level: Third-tier resources or services that are optional but important. Enhanced-level resources may produce minor } \\
\text { improvements in outcome but increase the number and quality of therapeutic options. Most procedures that improves clinical } \\
\text { outcome are available (i. e. biliopancreatic endoscopy, electrosurgical unit, polypectomy/mucosectomy, anesthesia back-up). }\end{array}$ \\
\hline III: Enhanced & $\begin{array}{l}\text { Maximal level: High-level resources or services that may be used in some high-resource countries or be recommended in } \\
\text { guidelines that assume unlimited resources. To be useful, maximal-level resources typically depend on the existence and } \\
\text { functionality of all lower-level resources. }\end{array}$ \\
\hline IV: Maximal &
\end{tabular}

After the initial ESGE cascade guidelines on non-variceal upper gastrointestinal bleeding (NVUGIH), we aimed this ESGE cascade guideline to standardize management of esophageal stenting for benign and malignant disease in low-resource settings $[2,5]$.

\section{Methods}

The cascade guideline methodology used has been described in previous cascade guideline papers [1,5]. Briefly, resource-sensitive recommendations were selected from the original ESGE guideline on esophageal stenting, but only those with an agreement of $50 \%$ or more for classification as being resource-sensitive by the International Affairs Working Group (IAWG) were included in the revision process [2]. This process was guided by six African experts from Ghana, Nigeria, and Ethiopia.

Subsequently, the IAWG, together with the first author of the original guideline, suggested a revision of the statements according to cascade methodology, for four predefined levels of resource availability ( Table 1 ) [6]. A modified Delphi process was then carried out with a panel of African gastroenterologists who were invited from a contact list of ESGE, WEO, and European national societies $[1,6]$. If a $75 \%$ agreement was reached for all four levels of care (adaptations), the statement was accepted [6]. If the panel members disagreed with one of the adaptations, they had the opportunity to add a comment; thus, if an adaptation failed to reach agreement from $75 \%$ of the panel, the statement was revised according to the advice from the panel members. Subsequently, a second Delphi round might be conducted to reach an agreement on all of the resource-sensitive statements. Furthermore, if any panel member was unable to respond to specific statements during the Delphi process, they could refuse to answer.
- Table 2 Characteristics of participants in the Delphi analysis.

Number of participants $(n=19)$

\begin{tabular}{|l|c|}
\hline \multicolumn{2}{|l|}{ Geographical area } \\
\hline - North Africa (\%) & $3(16)$ \\
\hline - Central Africa (\%) & $3(16)$ \\
\hline - East Africa (\%) & $6(32)$ \\
\hline - West Africa (\%) & $6(32)$ \\
\hline - South Africa (\%) & $1(5)$ \\
\hline Socioeconomic status of institution/hospital \\
\hline - High (\%) & $0(0)$ \\
\hline - Mid (\%) & $8(42)$ \\
\hline - Low (\%) & $11(58)$ \\
\hline
\end{tabular}

\section{Cascade statements}

\section{Statement selection}

Of the 18 recommendations in the original ESGE guideline, 11 were selected as being resource-sensitive by the IAWG. Four adapted cascade statements - one for each level - were created for each of the original recommendations, making a total of 44 adapted cascade guideline statements.

\section{The Delphi process}

Overall, 19 experts participated in the Delphi process. Details of the participants are provided in $>$ Table 2 . A $\geq 75 \%$ agreement was achieved for 41 of 44 proposed adaptations. Overall, three cascade adaptations of three recommendations involving surgery as an alternative form of treatment for malignant obstruction failed to achieve the $\geq 75 \%$ agreement level. Following the advice from the panel of experts, these statements underwent further revision as described below. 
- Table 3 Statements and recommendations.

1. ESGE recommends placement of partially or fully covered self-expanding metal stents (SEMSs) for palliation of malignant dysphagia over laser therapy, photodynamic therapy, and esophageal bypass (strong recommendation, high-quality evidence).

I. Best supportive care/palliative care

II. Surgery

III. SEMS

3. For patients with longer life expectancy, ESGE recommends brachytherapy as a valid alternative or in addition to stenting in oesophageal cancer patients with malignant dysphagia. Brachytherapy may provide a survival advantage and possibly a better quality of life compared to SEMS placement alone. (Strong recommendation, high-quality evidence.)

I. Best supportive care/palliative care

II. Surgery

III. SEMS

4. Esophageal SEMS placement is recommended as the preferred treatment for sealing malignant tracheoesophageal or bronchoesophageal fistula (strong recommendation, low-quality evidence).

I. Best supportive care/palliative care

II. Surgery

III. SEMS

5. Application of double stenting (oesophagus and airways) can be considered when fistula occlusion is not achieved by esophageal or airway prosthesis alone (strong recommendation, low-quality evidence).

I. Best supportive care/Palliative care

II. Best supportive care

III. Oesophageal stenting

8. ESGE suggests that SEMS placement with concurrent single-dose brachytherapy is safe and effective for relief of dysphagia (weak recommendation, low-quality evidence).

I. Best supportive care/palliative care

II. Surgery

III. SEMS

10. ESGE suggests consideration of temporary placement of self-expandable stents for refractory benign oesophageal strictures (weak recommendation moderate quality evidence).

I. Symptomatic treatment/best supportive care

II. Bougienage, ballon dilation, or surgery

III. SEMS

13. ESGE suggests that FCSEMSs be preferred over PCSEMSs for treatment of refractory benign esophageal stricture, because of their lack of embedment and ease of removability (weak recommendation, low-quality evidence).

I. Symptomatic treatment, best supportive care

II. Bougienage, ballon dilation, or surgery

III. FCSEMS

14. ESGE recommends the stent-in-stent technique to remove PCSEMSs that are embedded in the esophageal wall (strong recommendation, low quality evidence).

I. Symptomatic treatment, best supportive care

II. Attempt to remove PCSEMSs using conventional methods such as rat tooth forceps or APC

III. Stent-in-stent technique

16. If refractory benign esophageal stricture has not satisfactorily improved after two separate treatments with temporary stenting, ESGE suggests alternative treatment strategies such as self-dilation or surgical treatment (weak recommendation, low quality evidence). In poor surgical candidates, ESGE recommends self-dilation with rigid dilators (strong recommendation, low quality evidence).

I. Symptomatic treatment, best supportive care

II. Bougienage, surgery

III. Self-dilation

17. ESGE recommends that temporary stent placement can be considered for treatment of leaks, fistulas, and perforations. No specific type of stent can be recommended and duration of stenting should be individualized. (Strong recommendation, low-quality of evidence).

I. Symptomatic treatment, antibiotics, nill by mouth, or fluid diet

II. Endoscopic closure attempt with clips, or surgery

III. Stent placement

18. ESGE recommends considering placement of a SEMS for treatment of esophageal variceal bleeding refractory to medical, endoscopic, and/or radiological therapy, or as initial therapy for patients with massive bleeding (strong recommendation, moderate quality evidence).

I. Supportive care

II. Supportive care

III. Stent placement 


\section{Cascade adaptation}

Each original recommendation with the accepted adaptations is reported in Table 3 . The main resources that influenced adaptation of the original guidelines can be categorized as follows:

\section{Malignant strictures}

In many impoverished parts of Africa, malignant esophageal strictures are more often diagnosed in an advanced stage of disease [7]. For advanced tumor stages, palliative surgical options may be more readily available than stenting for treatment of malignant esophageal strictures.

At the basic level, only best supportive care is available and palliative treatment such as nasogastric feeding tubes or intravenous fluid supply may be the only available option.

At the limited level, treatment of symptomatic cancer varies from region to region, mainly depending on availability of surgery as a treatment option. Surgery can be offered to patients with resectable tumors and longer life expectancy who are fit enough to undergo surgery.

Stent placement should be offered to patients where the necessary infrastructure and expertise are available, usually at the enhanced level.

Additional barriers are represented by the following factors:

1. Training - lack of availability of expert gastroenterologists with the necessary technical skills for stent placement.

2. Infrastructure - lack of availability of stents, fluoroscopy, and other equipment involved in stent placement. Furthermore, lack of availability of brachytherapy/radiotherapy for treatment of malignant strictures.

\section{Benign strictures}

The most common causes of benign strictures in African countries include corrosive and peptic aetiologies as well as achalasia $[8,9]$.

Similar to treatment of malignant strictures, the lack of both surgery and endoscopy resources will hinder clinically relevant treatment at the basic level. On the other hand, at the limited level, periodic endoscopic dilation may be an affordable option. Also, surgical treatment should be considered, depending on its availability.

\section{Conclusions}

Most of the original recommendations for esophageal stenting of malignant and benign disease were successfully adapted to a cascade approach for resource-limited areas. The cascade guidelines addressed limitations that were related to infrastructural and human resources. For example, at the basic level, neither SEMS nor skilled gastroenterologists are available for treatment of esophageal strictures, therefore, best supportive care may be the only reasonable alternative. And even when expert gastroenterologists are available, technological resources such as fluoroscopy or brachytherapy may limit treatment of such patients. Palliative surgery may be an alternative, but also associated with extensive use of resources and presumably with high mortality. Finally, even when resources and expertise are available for endoscopic stenting or surgery, patients and their families may not be able or willing to pay for the high financial costs involved.

Two major limitations of the Delphi process need to be highlighted:

1. The total number of participants was low especially compared to the first ESGE cascade guideline on NVUGIH [5].

2. Some participants may have had limited experience and expertise in treatment of esophageal strictures or in the use of esophageal stents and brachytherapy/radiotherapy. This was reflected in the high number of total "don't know" answers ( $97 / 627)$ given by the participants.

\section{Acknowledgements}

Hanna Bayisa, Mohamed Borahma, Riadh Bouali, Tzeuton Christian, Samuel David, Nabil Debzi, Babatunde Duduyemi, Fikadu Girmagudissa, Berhane Meshesha, Yunus Miya, Prassad Modcoicar, Ruffin Ntounda, Olive Obienu, Emeka Ray-Offor, Paulos Shume, and Antoine Tshimpi are acknowledged as members of the Delphi Panel.

\section{Competing interests}

None

References

[1] Hassan C, Aabakken L, Ebigbo A et al. Partnership with African countries: European Society of Gastrointestinal Endoscopy (ESGE) Position Statement. Endosc Int Open 2018; 06: E1247-E1255

[2] Spaander MC, Baron TH, Siersema PD et al. Oesophageal stenting for benign and malignant disease: European Society of Gastrointestinal Endoscopy (ESGE) Clinical Guideline. Endoscopy 2016; 48: 939-948

[3] Thumbs A, Vigna L, Bates J et al. Improving palliative treatment of patients with non-operable cancer of the ooesophagus: training doctors and nurses in the use of self-expanding metal stents (SEMS) in Malawi. Malawi Med J 2012; 24: 5-7

[4] Thumbs A, Borgstein E, Vigna L et al. Self-expanding metal stents (SEMS) for patients with advanced oesophageal cancer in Malawi: an effective palliative treatment. J Surg Oncol 2012; 105: 410-414

[5] Karstensen JG, Ebigbo A, Aabakken L et a. Nonvariceal upper gastrointestinal hemorrhage: European Society of Gastrointestinal Endoscopy (ESGE) Cascade Guideline. Endosc Int Open 2018; 6: E1256E1263

[6] Milholland AV, Wheeler SG, Heieck JJ. Medical assessment by a Delphi group opinion technic. N Engl J Med 1973; 288: 1272-1275

[7] Come J, Castro C, Morais A et a. Clinical and pathologic profiles of esophageal cancer in Mozambique: a study of consecutive patients admitted to Maputo Central Hospital. J Glob Oncol 2018; 4: 1-9

[8] Mudawi HM, Mahmoud AO, El Tahir MA et al. Use of endoscopy in diagnosis and management of patients with dysphagia in an African setting. Dis Esophagus 2010; 23: $196-200$

[9] Thomas MO. Experience in oesophageal substitution in Lagos, Nigeria. Niger Postgrad Med J 2004; 11: 215-217 